\title{
Mujeres en el jazz en Chile. Modelización, régimen simbólico y trayectorias de género ${ }^{1}$ Women in jazz in Chile.
Modelling, symbolic regime and gender trajectories
}

\author{
por \\ Miguel Vera Cifras \\ Universidad de Chile, Chile. \\ veracifras@hotmail.com
}

\begin{abstract}
Desde sus inicios en el jazz chileno, las mujeres han atravesado por dos grandes regímenes simbólicos en tensión: sublimación y frivolización, respectivamente. En ese contexto, sea como semillas de liberación o sea como peligrosa expresión de decadencia, sus trayectorias de género debieron cursar dialécticamente tres modelos en su desarrollo vocal, siendo sucesivamente modelizadas, ya sea como cupletista, vedette y lady crooner, antes de pasar al formato de "cantante de jazz" en la década de 1960. El largo olvido en que sus existencias quedaron ha sido mucho más que un inocuo lapsus, involuntario o irresponsable, pues ha estado operando, en la práctica, como una amnesia colectiva y normalizada a partir de la óptica androcéntrica de un jazz profesionalizado y un discurso histórico que lo consagra.

Palabras claves: Jazz, mujer, modelización, régimen simbólico.
\end{abstract}

Since its inception in Chilean jazz, women have been traversed by two great symbolic regimes in tension: sublimation and frivolization, respectively. In this context, whether as seeds of liberation or as a dangerous expression of decadence, their gender trajectories had to follow dialectically three models in their vocal development, being successively modeled as cupletista, vedette and lady crooner, before moving to the format of "jazz singer" in the 60s. The long forgetfulness in which their existences remained has been much more than an innocuous lapse, involuntary or irresponsible, since it has been operating, in practice, as a collective and normalized amnesia from the androcentric optics of a professionalized jazz and a historical discourse that consecrates it.

Keywords: Jazz, woman, modelling, symbolic regime.

Desde sus orígenes el jazz representó la irrupción de una nueva cultura, procesada a partir de dos regímenes simbólicos en tensión: uno que buscaba integrar sus elementos disruptivos como semillas de liberación y goce; y otro que buscaba

1 Agradezco las lúcidas observaciones de Jazmín Vajra (Nancy Betancourt) y Bárbara Wilson, compañeras de ruta en esta investigación, a quienes dedico este trabajo. 
conjurarle como peligrosa expresión de decadencia. Sostenemos que hubo congruentemente dos dispositivos discursivos para resolver tal tensión: elevar el jazz a rango docto, serio, universal (sublimación) o restringirlo a género ligero (frivolización). Era una mirada disociada en civilización y barbarie, como extremos que se aman y se excluyen, expresada también en una doble lectura metonímica y patriarcal del cuerpo femenino y del jazz: por un lado era naturaleza libre e inocente, por otro, era fascinante carne del pecado y corrupción.

El cruce entre estos dispositivos (sublimación y frivolización) corrió en paralelo durante el desarrollo del jazz, y definió la circunstancia de género que debieron afrontar las mujeres asociadas al circuito. Un caso particularmente ilustrativo es el ocurrido con las cantantes. Haciendo un recuento muy breve, podríamos decir que en conjunción y en intersección con lo anterior, las cantantes cruzaron tres espacios de acción, tres etapas o modelizaciones en su desarrollo vocal y acercamiento al jazz: el modelo español de la cupletista (impostación vocal lírica y corporalidad recatada, elegante), el modelo francés de la vedette (voz atiplada, chillona, y cuerpo impúdico semidesnudo), y finalmente, el modelo norteamericano de lady crooner (voz sin estrés lírico, natural, cuerpo elegante, semicubierto y sensual). Cada uno de estos modelos obedecía a ciertos patrones culturales más amplios, que definieron el contexto en que las mujeres ingresaron al campo del jazz. Etapas y modelos se irán superponiendo y solapando dialécticamente, en un proceso en el que emergerá posteriormente la categoría de "cantante de jazz", cuya cristalización en Chile ocurrirá a partir de la década de 1960, con Sophie Brown como uno de sus más notables y recientemente reconocidos hitos.

Traspasando el umbral de escuchar a la mujer "con los ojos"2, lo cantabile irá gradualmente adquiriendo protagonismo y autonomía, gracias a las tecnologías de amplificación, el cambio tonal de la voz, la ralentización del ritmo (de fox, a slow fox, fox-blue ${ }^{3} \ldots$ ), la fragmentación musical del género chico, la expansión de las letras colonizando la forma canción y la aparición de la cancionista, entre otros factores.

Tanto el régimen simbólico como las redes de modelización, orientadas por una óptica androcéntrica, operaron como mecanismos de subjetivación y representación para/de/en las mujeres, introyectándose tanto en el metatexto crítico/ historiográfico ${ }^{4}$ del jazz como en el paratexto ${ }^{5}$ periodístico, este último especialmente poblado de imágenes y estereotipos femeninos, reproductor del labeling (rotulación o etiquetación) que ha modelado históricamente las interacciones entre hombres y mujeres en el circuito de jazz en Chile.

2 Delannoy 2005: 32.

3 En 1941 Malú Gatica cantaba el fox-blue "Ángel de amor" y el slow foxtrot "La canción de la noche", ambas editadas en partituras por Casa Amarilla.

4 Para metatexto historiográfico ver Mignolo 1981: 358-402. "El metatexto define la actividad realizada y también los rasgos o propiedades de [un] texto en relación con su pertenencia a determinada clase: [...] los tratados historiográficos para el caso de la historiografía, ilustran lo que llamamos metatexto" (Cuneo 1998: 90). Se incluyen en él expectativas, principios y requisitos que deben cumplir operativamente los textos.

5 "El paratexto es toda la información que circunda la obra y que influye en los modos en que esta es comprendida. Son [...] los comentarios incluidos en los cuadernillos de CD o los que realizan los presentadores de radio o televisión”. López Cano 2007: 8. 


\section{MODELIZACIÓN Y RÉGIMEN SIMBÓLICO EN LA EXPERIENCIA DE GÉNERO}

Modelización y régimen simbólico constituyen los dos grandes ejes discursivos (de representación y de expresión) que orientaron y regularon la representación y las prácticas de mujeres vinculadas al jazz en Chile, tanto en la creación y difusión como en la enseñanza. Así, la mujer fluctuó (con matices) entre el estereotipo de mujer sensual, elegante, seductora, usualmente cantante, y la mujer exonerada de tales exigencias, ya sea por un rol cómico (solista o coral) o por su rol instrumental o vocal docto. En su desarrollo, el cuerpo femenino y su expresión procesarán la dicotomía sacralizante versus banalizante, resolviendo en cada caso una particular articulación personal respecto del régimen simbólico que pone en tensión estos dos impulsos (el sublimante frente al frivolizante), de acuerdo con cada una de las fases o modelos geosocioculturales asociados, y según las modelizaciones, "actividad social y política que se inscribe en las lógicas de los actores y las decisiones colectivas, por encima de la consideración de modelo como objeto [...] puramente cognitivo" 6 , así como de las circunstancias biográficas específicas de cada una de las protagonistas.

Estos modelos, anteriores a la cantante de jazz propiamente tal, fueron sujetos de negociación intersubjetiva y cultural, y funcionaron en intersección con los dispositivos discursivos aludidos (ver Tabla 1).

TABLA 1

RÉGIMEN SIMBÓLICO/MODELIZACIÓN

\begin{tabular}{|c|c|c|c|c|}
\hline \multicolumn{5}{|c|}{ Modelización } \\
\hline \multirow{3}{*}{ 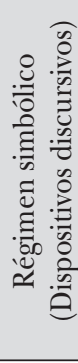 } & & Modelo español & Modelo francés & Modelo norteamericano \\
\hline & Sublimación & $\begin{array}{c}\text { Etapa del cuplé clásico: } \\
\text { impostación vocal lírica } \\
\text { y corporalidad recatada, } \\
\text { elegante. }\end{array}$ & $\begin{array}{c}\text { La vedette elegante y } \\
\text { exótica: voz educada, } \\
\text { y cuerpo elegante } \\
\text { semidesnudo. }\end{array}$ & \multirow{2}{*}{$\begin{array}{c}\text { Voz sin estrés lírico, } \\
\text { natural, cuerpo elegante } \\
\text { semicubierto y sensual. }\end{array}$} \\
\hline & Frivolización & $\begin{array}{c}\text { Etapa del cuplé } \\
\text { sicalíptico: voz atiplada, } \\
\text { chillona, y cuerpo } \\
\text { impúdico semidesnudo. }\end{array}$ & $\begin{array}{l}\text { La vedette erótica: voz } \\
\text { atiplada, chillona, } \\
\text { y cuerpo impúdico } \\
\text { semidesnudo. }\end{array}$ & \\
\hline & & \multicolumn{2}{|c|}{$\begin{array}{l}\text { Registro alto } \\
\text { a soprano }\end{array}$} & $\begin{array}{c}\text { Registro mezzosoprano } \\
\text { a contralto }\end{array}$ \\
\hline
\end{tabular}

6 Modelizar es interpretar ciertos elementos o fenómenos de acuerdo con un modelo. Modelización es la actividad de modelizar de acuerdo con ciertos intereses o finalidades sociales determinadas. "Cuando hablamos sobre nuestra vida, estamos también modelizándola reflexivamente [...] los individuos se apropian y cultivan socialmente y modelizan cognitivamente) sus propias realidades" (Vizer 2009: 10). Entendemos por modelización, entonces, el aprendizaje social por modelado simbólico propuesto por Bandura (1977: 37). Las mujeres jazzistas habrían incorporado conductas signadas como "femeninas", siguiendo modelos culturales euronorteamericanos que circulaban con la mediación periodística y las hablas del circuito. 


\section{PATRONES DE ENTRADA}

En nuestro medio las primeras mujeres en relacionarse artísticamente con el jazz provienen del teatro cómico y la revista, géneros menores activos a inicios del siglo XX: tiples de jazz, bailarinas y actrices cómicas que utilizaron repertorio de jazz. A veces representadas como un colectivo asociado al mundo de la diversión: somos las bailarinas, hermanas del jazz/con nosotras vive la frivolidad, bebemos champaña allá en la cena de la loca madrugada del moderno cabaret, decía el foxtrot "Lección de baile", escrito por el chileno Daniel de la Vega en 1928 para la revista musical Fanfarria, estrenada simultáneamente en dos teatros (Santiago y Coliseo) de la capital. Cinco años antes, en 1923, se presentaba la compañía Selected Jazz Band y 10 jazz girls en el American Cinema, de calle Arturo Prat, en Santiago. Entre 1931 y 1935 la Orquesta Húngara de Señoritas "se lucía con bailes de jazz" a sus 10 integrantes en el teatro La Comedia de Santiago. Otra vertiente asumida por las mujeres fue la composición de música bailable, principalmente en partituras de foxtrot, one-step y shimmy.

A diferencia de la ópera, género elevado según la élite cultural, el jazz correrá inicialmente la misma suerte que la música popular, siendo asociado a los bailes y al género frívolo (cuplé español y revista francesa, sucesivamente), haciendo causa común con el espectáculo licencioso y el bataclán, canónicamente "menor" frente a la música "seria", al Arte con mayúscula. Este último considerado moralmente superior, de acuerdo con el juicio docto cuyo patrón hizo que el jazz quedara asociado en un primer momento y por mucho tiempo al "tabaco fuerte y fétido

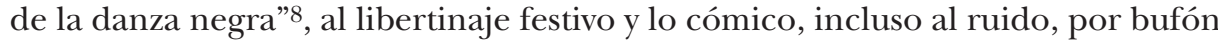
o en oposición a la música. Lo cómico asociado a los ritmos de jazz aparece inicialmente vinculado con connotaciones prohibidas, sensuales y hasta pecaminosas, contrarias a la moral católica de las élites conservadoras que ven en esta clase de espectáculos un desenfreno condenable para las jóvenes de buena familia.

Inserto en la matriz histórica de un desarrollo musical orientado por los valores del arte canónico occidental, academicista, contemplativo e intelectual ${ }^{9}$, el jazz irá despegándose del baile, de los cuerpos, y sucesivamente escalando posiciones en la evaluación de los críticos, quienes aplicando el canon clásico, concederán gradualmente al jazz las categorías de universalidad, seriedad y profesionalismo. La arteria que nutre el prejuicio docto es la idea de que el jazz puede llegar a ser una música seria, robusta, universal y abstracta. Es decir, una música institucionalmente válida bajo un canon hegemónicamente monológico, blanco y masculino ${ }^{10}$, sustrayéndolo así del torrente vulgar y degradado de la música popular o comercial al que el jazz fue adscrito ${ }^{11}$ cuando fue primordialmente música de baile o propiamente baile. Canonizar el jazz implicó, por defecto, olvidar o neutralizar

\footnotetext{
7 González y Rolle 2003: 325.

8 Mistral 1979: 120.

9 Green 2001: 106-109; 221-224.

10 Tomlinson 1991: 242.

11 Adorno 2008: 83.
} 
inopinadamente, ya sea por vía de la exotización ${ }^{12}$ o el exoticismo ${ }^{13}$, su variante frívola y corporal (el lowbrow jazz), para posteriormente proceder a delimitarlo como una forma legítima de arte, des(re)calificando las primeras manifestaciones del jazz como preformas, circunscritas a una prehistoria o etapa primitiva.

Este proceso, que ocupó todo el siglo XX, fue vivido por las mujeres desde su particular ubicación en la trama social, regida por una axiología androcéntrica que ha comenzado recientemente a ser desmantelada. El filósofo Bruce Ellis Benson ha (d)enunciado la ideología patriarcal según la cual: "el jazz (como las mujeres) es [o puede ser] tan bueno como la música artística occidental (o como los hombres)" 14 .

Por su parte, analizando textos periodísticos publicados entre 1994 y 1999 en Colombia, Juan Sebastián Ochoa examinó el modo en que el canon del jazz ha sido construido en su país desde el discurso periodístico, académico, crítico y los espacios de comunicación masiva, concluyendo que "este tipo de construcción de canon presenta unos posicionamientos que se pueden leer en términos de exclusión y diferencia, tanto en términos de clase y estatus social como de raza y género" 15 . El autor ha caracterizado el canon de jazz con once rasgos, entre estos destacan: ser considerada música culta, absoluta, universal, para especialistas, de gran libertad creativa, exaltación de la personalidad individual, con una "historia oficial" asociada a lo mítico, una valoración del jazz como signo de distinción, de gran sofisticación profesional, académica, y una alta valoración moral o espiritual.

El ingreso del jazz a la alta cultura como fine art (a contar de los años 1930, según Sargeant ${ }^{16}$ ) implicó considerarlo como música autónoma. Esta autosuficiencia se ha identificado con la visión androcéntrica del mundo, es decir, música superior, original, genial, compleja y (al igual que la música clásica) "pura"17 e instrumental. Agrega este autor que "la actividad de cantar la realizan [en el jazz, mayoritariamente] las mujeres"18. Coincide en esto con los estudios realizados por su compatriota Alejandra Quintana, para quien el canto se mantiene como marca de femineidad, mientras que a nivel de una simbología de género, sonoridad y forma, se establecen "relaciones duales en las que lo agudo y liviano es femenino, y lo grave y voluminoso es masculino"19. Esto trae aparejado, además de los tipos de voces según su tono, una distribución de los instrumentos en la que el trombón, el contrabajo, la tuba y la trompeta se definen como no adecuados para las mujeres.

Enfrentadas a ciertas resistencias y tensiones al momento de articular el tiempo reproductivo y productivo de sus proyectos biográficos, las mujeres han debido

12 Ellis Benson 2005: 97.

13 Schuller 1998: 283.

14 Ellis Benson 2005: 94.

15 Ochoa 2011: 7.

16 Sargeant 1975: 250.

17 Ochoa 2010: 14.

18 La investigación de la socióloga Bernardita Ihnen (2012) confirma lo mismo para el medio chileno.

19 Quintana Martínez 2009: 177. 
afrontar lo que se ha llamado la "doble adscripción identitaria"20: la tensión entre su inserción laboral y sus responsabilidades familiares. Profesionalizarse como instrumentista (de una orquesta de jazz, que actúa de noche y ensaya fuera de casa durante el día) resultaba hasta bien entrado el siglo XX incompatible o incluso contradictorio con las obligaciones de género ${ }^{21}$, y en muchos casos con el estatus social, por esta razón no hay dedicación exclusiva ni continuidad en sus carreras hasta entrado el siglo XXI. El canto de las mujeres, a diferencia de la práctica de la música instrumental, fue considerado una extensión del "don" natural de su sexo, una "gracia" musical innata que puede ser trabajada como parte del "arte de agrado", propio de sus labores domésticas o asociado a la pedagogía musical como extensión del rol materno y reproductor dentro de sus hogares, a diferencia del régimen instrumental asociado al control del cuerpo mediante artificio externo. La prerrogativa de la música instrumental quedó para los hombres, cuyos instrumentos implicaban traslados, ocupación de espacios (salas de ensayo, bodegas, talleres, etc.), en nada compatibles con el recato oikocéntrico de las mujeres.

La transición desde el ritmo (al que las mujeres ingresan corporalmente por medio del baile) hasta el predominio de la melodía en la representación del jazz abrirá un espacio especialmente receptivo para la forma cantada. Por oposición, cuando la mujer asume un instrumento "incompatible", como la batería (connotativamente asociada al boxeo), se erige en figura disonante, vocera del ruido social de la modernidad, por lo que la mujer es emblema. En 1927 el chileno Armando Mock publica Señorita Charleston, una comedia donde Dorita, su protagonista, recibe el apodo que da nombre a la pieza por lo "moderna" que es. Se trata de una joven impulsiva, fumadora y practicante de boxeo. La identificación del baile charleston y el ritmo (ella toca batería en la obra) con la nueva moralidad y su tipo femenino, es congruente con la creciente devaluación de la tradición europea, frente a ello este tipo social de mujer se erige como símbolo de la nueva sensibilidad, ícono del nuevo paradigma social: "Soy la perfección del siglo", proclama la protagonista.

Otro chileno, Pascual Brandi Vera, publicó en 1935 su novela Jazz, donde encontramos alusiones despectivas respecto de esta música, asociada al "timbaleo" y "la percusión diabólica del saxofón”. La ácida dedicatoria del prólogo asocia el jazz al "engaño que es criminal, por lo pútrido y venenoso de la droga”, espetando de colofón: "A vosotros, pues, mi jazz que si va descompuesto y venenoso no lo estará más que el tóxico que se propaga”, criticando de paso a las "Mujeres modernas [que saltan] a la tribuna del boxeo, para diseñar el nuevo espíritu femenino, caricaturesco y más bien hermafrodita" 22 .

En resumen, primero el baile y las bailarinas; luego, las actrices y el teatro; finalmente las cantantes y la vocalización jazzística. Las mujeres irán ingresando gradualmente al campo y proyectándose mediante los sucesivos modelos geoculturales de la modernidad y hegemonía: española, francesa y norteamericana,

20 Araujo 2009: 191 (en referencia a Guadarrama y Torres 2005).

21 Citrón 1993: 81.

22 Brandi Vera 1935: 7. Agradezco a Álvaro Menanteau el haberme facilitado el texto, cuyo "hajazz-go" tuvo lugar la mañana del sábado 27 de octubre de 2012 en el Persa Bío-Bío, Santiago de Chile. 
transitando desde la tiple cupletista hasta la vedette y luego la lady crooner para llegar, posteriormente, a la forma "cantante de jazz", cuya cristalización ocurre a partir de la década de 1960. El presente artículo se focaliza en las precantantes de jazz, anunciando a la cantante y quizás atisbando la búsqueda postmoderna de un jazz gilánico ${ }^{23}$.

\section{EL MODELO ESPAÑOL}

\subsection{Generalidades}

Bajo la influencia en Chile (durante las últimas décadas del siglo XIX y hasta entrada la primera mitad del siglo XX), del llamado género chico y sus derivados (sainetes, operetas, cuplés), las cantantes siguieron el modelo de las figuras espanolas que visitaban el país, destacadas por su vestuario elegante y sus capacidades histriónicas. Asociadas al arte lírico, estas cantantes se presentan en los principales teatros de Santiago y Valparaíso. Tras una primera etapa de "cuplé sicalíptico", erótico, escandalizador (que reemergerá con el vedetismo), el desborde vino a ser rápidamente neutralizado y reprimido por el llamado "cuplé tradicional”, que validaba la voz femenina bajo la impostación lírica operática, cubriendo rollizos cuerpos mediante frondosos trajes en el marco escénico de la ópera menor.

Durante la regencia del modelo español se cantaban y bailaban shimmys, one-step, two-step (las formas del jazz comercial de la época) por cantantes del repertorio cupletista como números aislados o insertos en las mismas operetas, revistas o zarzuelas. Ejemplo de ello es el caso de Esperanza Iris, "la reina de la opereta", interpretando el shimmy "Reliquias de amor" en Santiago. O bien "A fines de los años 20, La Chilenita [que] fue la primera cupletista que grabó disco en el país, iniciando junto a grupos de huasos y orquestas de jazz, las grabaciones del sello Victor en Chile"24. Además, no era raro pasar temas de la zarzuela al jazz. Ejemplo de ello fue el one-step "Los del jazz”, con motivos de la zarzuela La Alegría de la Huerta que circulaba en Santiago con arreglos y letra de Roberto Retes B.

Alicia Vignoli, por su parte, cantaba en la década de 1930 "Bocinas de automóvil", un exitoso shimmy de la Compañía de Revistas Sarmiento, que actuaba en el Teatro Esmeralda de Santiago, mientras Betty Lupetty interpretaba el foxtrot "Al mal tiempo, buena cara”. El jazz estuvo presente en operetas y cuplés, interpretados por todas las figuras extranjeras que visitan el país y, poco a poco, por las intérpretes locales. Respecto de las zarzuelas, no está de más señalar que, aparte de piezas de jazz, solían incluir tangos, valses y pasodobles entre sus números musicales.

23 Gilania (Gylany). Término creado por Riane Eisler. GY deriva de la raíz griega gyne, o "mujer". An deriva de andros, "hombre". La letra "l" entre ambas tiene un doble significado. En inglés representa la vinculación entre ambas mitades de la humanidad, link en inglés significa vínculo. En griego deriva del verbo lyen o lyo que, a su vez, tiene un doble significado: solucionar o resolver, y disolver o liberar.

24 Peña 2008: 304. 


\subsection{Autoría femenina en las letras de música popular ${ }^{25}$}

Una de las primeras formas de legitimación y autoría femenina en la música popular del siglo XX fue la composición de letras y partituras musicales para piezas de foxtrot, shimmy y one-step, utilizadas ya sea para uso doméstico o para acompañar exhibiciones de cine antes de la llegada del sonido en 1933. El uso de partituras corresponde a lo que llamaríamos "música popular letrada", algunas grabadas en discos 78 RPM, y otras solo transcritas en partituras. Hay registro de las pianistas cinéfonas en Valparaíso y también de la abundante presencia femenina en la radio. Ya en plena Belle Époque, Amelia Palma de Pérez, sobresalía como cupletista, compositora y pianista ${ }^{26}$, incluyendo en su repertorio el one-step. Las piezas que se editaban en Valparaíso, Concepción y Santiago contenían por lo general letras y música para estos bailes. La poética era de efectos fáciles, incluso algo simples: los motivos literarios, sencillos, recurriendo con frecuencia a cierta cursilería modernista. Constantemente lo femenino aludía a flores, aves o pájaros, a situaciones amorosas donde la identidad femenina oscila entre la sumisión al amor masculino y su contracara, la cruel femme fatale, dominante y exigente. No hay irreverencia o subversión, sino más bien lugares comunes y poesía lene.

En la modalidad canción foxtrot encontramos a la chilena Mercedes Orrego, quien compuso la música y letra del fox "De mi tierra soy la flor", grabado en disco Victor N ${ }^{\circ}$ 90-0538-A y editada por Editorial Casa Amarilla. "Soy chilena, chilenita / soy la espiga del trigal / de mi tierra soy la flor" afirma la composición, cuya letra alude a una mujer morena que es "paloma fiel", hija de una luna "hechicera" que alumbra la escena donde tiene lugar el encuentro nocturno con su "negro" cuando salen a bailar. "Negro" tiene aquí probablemente el sentido de moreno, metonímicamente hombre de raza negra, asociado a las connotaciones de oscuro, secreto y seductor, en alusión, probablemente, al modo familiar con que en Chile se suele llamar al varón en la pareja. La subcultura nocturna como zona de tolerancia moral será motivo frecuente en estas composiciones. Orrego compuso además: “¡Ven a mí!” y "El canto del cucú”27. En el primero de ellos, la composición adopta como hablante una voz masculina y, en el segundo, un hablante también masculino refiere el canto de un pájaro ya silente y dormido (non vigilante) en la liberada noche de amor.

El tema de la noche invitando o seduciendo al amor era recurrente. Fue el caso del texto del shimmy "La danza de las libélulas", compuesto para la opereta homónima del compositor austrohúngaro Franz Lehar, por la cantante lírica, letrista, compositora y arreglista Aurora Peris. El texto publicado hacia 1923 por Casa Amarilla reza: "La noche ya su manto echó / y su penumbra invita al amor /

25 Música popular transmitida en partituras (que se oía por los ojos). Durante las primeras décadas del siglo XX, convivieron música popular transmitida en partituras publicadas, junto con registros de música y oralidad cómica grabados en acetatos de 78 RPM.

26 González y Rolle 2003: 203 y 545.

27 La primera, una canción foxtrot grabada en disco Victor y publicada por Casa Amarilla en 1944. La segunda, un foxtrot grabado en disco Victor $\mathrm{N}^{\circ}$ 90-0324 y publicado por Casa Amarilla en 1945 (González y Rolle 2003: 264). 
la blanca luna inunda de poesía nuestra canción / vamos a cantar y ensimismados con su dulce melodía / a nuestro amor podremos rienda suelta dar / la noche invita al apachey a gigolette..." (es decir, el asaltante y la chica fácil, respectivamente, en la jerga parisina de esa época).

El shimmy, paralelo al estilo Chicago en el jazz, adquirió cierto carácter provocativo que lo hizo condenable para los sectores conservadores de la época. Será simultáneo al arranque del crooner (propiamente masculino, de ahí el marcador lady para las mujeres), modelo inaugurado en Chile por José Bohr al grabar el shimmy "Y tenía un lunar", en su versión cantada28. En esta modalidad encontramos a Josefina Barbat, española que había emigrado a Estados Unidos, luego a Argentina para, finalmente, radicarse en Chile a fines de los años 20. Barbat escribió letras e hizo los arreglos para piano de numerosos shimmies, one-steps y foxtrots, por lo menos entre 1927 y 1934. Algunas de sus piezas fueron grabadas en discos Odeón, Victor, Brunswick o Columbia, operando en paralelo con la publicación de las partituras para piano que se vendían para el uso doméstico. Esta última actividad estaba asignada especialmente a las mujeres, quienes ejercían la labor pianística como una de las domésticas "artes de agrado" propias de su educación ${ }^{29}$. El espacio privado estaba presente no solo en la recepción de estas composiciones, sino también muchas veces en las circunstancias de creación.

Josefina Barbat escribió también letras (en castellano) para foxtrots que acompañaban la exhibición de películas extranjeras en la capital. Ella vivió la intensa vida social santiaguina de esos años, componiendo no solo piezas de jazz sino valses, canciones y repertorio español. Una curiosa anécdota vincula a esta notable compositora con la poetisa y compositora María Cristina Menares, madre de la cantante de jazz Rita Góngora:

"Renato Menare Rowe, coleccionista y estudioso de la música popular, contó al autor [Juan Marino] que estando en una fiesta familiar hace de esto pocos años, conoció a una dama de nombre María Cristina Menares, la que luego de algunos intercambios de ideas respecto a la música pretérita y moderna y de haber escuchado el vals Recordar... recordariola, original de Josefina Barbat, la dama le declaró que el tema le pertenecía. Dijo la señora Menares que ella lo había creado como una parodia de un filme que se llamaba Recordary que se exhibía en Santiago por esos años de 1933 o 1934. Cuando se le ocurrió el tema, estaba presente en esa reunión Josefina Barbat; la señora Menares tarareó el vals siendo recogido por la Barbat en el papel pautado, con conocimiento de la otra. En las etiquetas aparece el nombre de doña María Cristina Menares, que recibió de parte de la catalana un suculento cheque como derecho de autoría por una única vez del tema, cuya maternidad se atribuye a la Barbat. Este gesto de honestidad pone

28 González y Rolle 2003: 264.

29 En relación con las llamadas "artes de agrado" o "artes de adorno”, ver Errázuriz 1994: 39 y también González y Rolle 2003: 123. Acerca del rol doméstico asignado a la música compuesta e interpretada por mujeres, la musicóloga chilena Fernanda Vera ha rastreado la tradición del salón decimonónico en diversos "álbumes musicales para señoritas" de la época (ver en la Biblioteca Nacional Digital de Chile, http:/ /www.bibliotecanacionaldigital.cl/bnd/612/w3-article-349131.html, consultado el 25/05/2018). 
de manifiesto el sentir de los artistas cuando reconocen, aunque solo sea en forma de un cheque, la ayuda prestada por terceros a sus creaciones" 30 .

\section{EL MODELO FRANCÉS}

\subsection{Generalidades}

Considerado más irreverente y moderno, este modelo se consolidó con la influencia de Josephine Baker y las formas revisteriles parisinas, fascinadas por la negritud y el exotismo. A diferencia de la cancionista o cupletista española tradicional, ahora la mujer se desnuda. La carnalidad (ojalá morena) es expuesta y apreciada por un público esencialmente masculino que busca risas y excitación erótica en lo exótico. Se forman coros de tiples, es decir, mujeres de voz muy aguda, incluso chillona, que sobresalen por sobre la masa orquestal con un volumen suficiente para ser escuchadas por sobre el vocerío y la algarabía masculina. Las tiples provenían del modelo español de la zarzuela y el cuplé. Por otra parte, en la música negra existía la tradición de los shouters o gritadores.

El jazz continuó asociado al género cómico, erótico y revisteril hasta la segunda mitad del siglo XX. El modelo francés mantuvo la voz de la mujer en continuidad escénica con el modelo español, solo que aquí el cuerpo deja caer sus ropas y se expone desnudo, asociando ahora el atiplamiento chillón de la voz con las necesidades de comicidad y erotismo desopilante.

\subsection{El vedetismo y el jazz}

A comienzos de los años 20 se inició el reinado del vedetismo. Uno de sus primeros ejemplos es la presentación en Santiago de la Select Jazz Band de Renato Valenzuela, donde junto con un actor cómico que tocaba serrucho, se presentaba la Orquesta de Enrique Di Lorenzo y diez jazz girls, que al decir de Juan Marino "escandalizaban a las pocas mujeres que osaban concurrir al espectáculo"31.

De estructura muy dúctil, la revista se caracterizaba por lo que González y Rolle denominan "carácter yuxtapuesto o aditivo", pues dependiendo de las circunstancias podía alterar arbitrariamente su forma. Un ejemplo de ello se encuentra en la obra Acuarelas de Osmán Pérez Freire, que incluía en su tercer acto una presentación de jazz band.

Durante la belle époque la revista se nutrió de exotismo y etnoerotismo. Esto último constituyó el capital simbólico de la vedette Josephine Baker, cuyas giras por distintas partes del mundo la trajeron a Chile en 1929, 1947 y 195232. Una vedette era una artista que cantaba, actuaba y bailaba. Dotada de gran atractivo físico, era la primera figura de las revistas. El atractivo del cuerpo femenino erotizado

30 Marino y Martinic, s/f, p. 142.

31 González y Rolle 2003: 160.

32 La cantante de jazz Rita Góngora recuerda haber visto, durante su infancia, una foto de la Baker visitando su casa, recuerdo que ha permanecido (probablemente mitificado) hasta hoy. 
despertaba la fantasía del público eminentemente masculino, que además valoraba el exotismo como escapismo imaginario. Tanto en el modelo español de la cupletista como en el francés de la vedette, la frivolización de la mujer tenía directa relación con la necesidad de encontrar allí a la "otra”, la amante ajena a las rutinas de la casa, excepcional y extravagante en el ensueño erótico y afectivo de las necesidades masculinas. La infantilización de la voz (que para estos efectos se agudiza) es una variante de este modelo, connota inocencia y debilidad seductora. Voces tiples, chillonas, altas, o sopranos infantilizadas como el registro de la Baker, connotan en muchas revistas la imagen acústica de un dominador y una odalisca sumisa y erotizada.

En 1937 Hellen L. Kaufmann caracterizó a la música de jazz como una joven, coqueta y sensual con quien los hombres buscan escapar cuando la esposa (la música clásica, docta, seria) se volvía aburrida y exigente. En su libro From Jehova to jazz. Music in America from psalmody to the present day, publicado en New York a fines de los años 30 (reeditado en 1968), Kaufmann afirmaba:

"El jazz es, a la larga, una caprichosa loca [...] Ella está disponible para muchos amantes de la música en el rol de maestra con la que escapan cuando la esposa (la música seria) envejece, cuando sus pechos caen y se torna un poco fastidiosa y exigente; cuando ellos se quejan de ser malentendidos, eluden tener una esposa y buscan una junta con la maestra. De todos modos, las dos están completamente conscientes de la existencia de "la otra" o rival y, en general, la esposa no muestra desprecio por el uso de algunas de las técnicas de la maestra, y viceversa" $"$.

\section{EL MODELO NORTEAMERICANO}

\subsection{Generalidades}

A partir de 1938 (y hasta 1948) se dio, de acuerdo con lo señalado por Francisco Deza, lo que él denomina "renacimiento de las formas tradicionales" del jazz. "Esta época se caracteriza por el comienzo de estudios serios, el descubrimiento de viejos músicos olvidados, y la difusión en el público de la existencia de 'un jazz verdadero' en contraposición del 'jazz comercializado" "34. Tal división a fines de los años 30 adoptará en Chile la forma de una rivalidad entre hot jazz (para algunos el verdadero) y el "jazz melódico" (para otros, el comercial). Se decía que la improvisación, y la personalidad asociada a ello, era rasgo central del hot. El scat, que había dado a conocer Louis Armstrong en 1926, era la improvisación en el canto. Hasta donde hemos investigado no hubo práctica de scat de manera preferente en Chile, salvo parodias cómicas, como la de Ana González en $1943^{35}$.

33 Traducción del autor. La misma oposición, un poco más extrema, entre "prostituta" (arte comercial) y "vieja hacendosa" (arte no comercial) la encontramos en Panofsky 1995: 120.

34 Deza 1964: 6.

35 Disco RCA Victor, 90-0169 A. 
Posteriormente, a mediados de la década de 1950, "la práctica del jazz en Chile se dividió en [...] dos modalidades claramente diferenciadas [...] el jazz tradicional [que gustaba de los] estilos históricos del jazz como Nueva Orleans, dixieland y Chicago [frente al jazz moderno representado por el bebop]"36. La dicotomía tradicional/moderno y arte/no arte (o comercial) se reactivaba dando lugar a formatos corales u orquestales, derivados en cuatro articulaciones posibles: tradicional-arte, tradicional-comercial, moderno-arte y moderno-comercial. El mercado musical ubicará a las mujeres preferentemente en las formas comerciales o melódicas, lo que tendrá consecuencias al interior del circuito de jazz, en la medida que esta música buscaba legitimarse como arte, despreciando las formas comerciales-melódicas y relevando la improvisación vocal en el bebop vía scat.

"Los cultores del jazz tradicional reivindicaron el valor de la melodía y la improvisación colectiva, al considerarla como la esencia del jazz original en conjunción con el espíritu emotivo del negro spirituals" 37 .

Asociado al jazz original o clásico ${ }^{38}$, el negro spiritual se cantaba con un formato vocal de cuatro o cinco voces, con impostación lírica. Desde la vereda más comercial del swing (considerado también parte de un renacimiento en su momento) ${ }^{39}$ aparece la lady crooner, que en Chile fue homologada imprecisamente por los medios periodísticos a la cancionista o cantante melódica. En ambos casos, el dominio del repertorio norteamericano implicaba cierta destreza con el idioma inglés (por lo menos, fonética), cualidad que restringe el universo social de postulantes a tal función. Si antes el jazz era posible para bailarinas y tiples, vedettes y actrices cómicas de clase media o baja, ahora la lady crooner era con frecuencia mujer de clase alta o media alta, con dominio idiomático, cultura cosmopolita, alguien que muchas veces evitará (por censura de sus distinguidas familias) aparecer con su nombre real en la prensa escrita.

\subsection{Las primeras lady crooners en Chile}

Así entonces, superando los prejuicios sociales ante la música popular asociada a la vida nocturna (prohibida para las mujeres de buenas familias), las pioneras comenzaron a aparecer. Según cuenta Osvaldo Muñoz Romero (Rakatán), testigo de la época ${ }^{40}$ :

36 Menanteau 2006: 83 .

37 Idem.

38 No obstante, el crítico norteamericano Winthrop Sargeant afirma que el spiritual tiene más en común con el hot jazz que con la interpretación operática de negros educados.

39 Jean Tarse, redactor de un texto enciclopédico sobre jazz en 1959 habla de cuatro eras: el período clásico (1917-1925), una edad media (1925-1935), un renacimiento (1935-1940), que corresponde a la era del swing y el revival del jazz tradicional, y un periodo barroco (1940 en adelante hasta el bebop). Jazz.Marabout Flash, Editions Gérard et C', Verviers, 1959: pp. 44-45.

40 Muñoz Romero 1986: 16. 
"Entre las chilenas que primero se atrevieron a desafiar los prejuicios del ambiente high de la capital, destacó la presencia de Dixie Lane, una joven recoletana que después destacó en el radioteatro y en la locución. Ella no fue otra que Mirella Latorre, hija del escritor Mariano Latorre [quien] cantaba junto a la Orquesta de Lorenzo D'Acosta".

A los 17 años, en 1936, había comenzado a presentarse como lady crooner en un local llamado Boyarín con la Orquesta de Lorenzo D'Acosta, anunciada como Orquesta Saint Lawrence. "Cantar con orquesta en un local nocturno era realmente escandaloso en esos momentos, y tuve muchas y muy duras críticas. Afortunadamente, tanto mi padre [...] como mi madre nunca se molestaron o escandalizaron por nada de lo que yo hacía. Por el contrario, lo celebraban...", declaraba en una entrevista en $1953^{41}$.

La joven Mirella Latorre Blanco vivió el entorno cultural de su padre con quien, incluso siendo ya crooner, aparecía de vez en cuando en el restaurante La Bahía ${ }^{42}$ causando admiración por su belleza. Recién egresada del bachillerato comenzó a actuar con un grupo de amigos aficionados, con una primera presentación en Pucón el verano de 1936, después de ello estuvo en radio Chilena haciendo radioteatro durante parte del verano. Después de dos o tres meses, surgió la idea de ser crooner. "Empezó a cantar en casa, en la calle, en el baño. Era inquieta. Un día decidió llamarse Dixie Lane y se fue a ensayar jazz”. Así relata la nota de Jacobo Jara presentada como apuntes biográficos acerca de "Mirella Latorre a contraluz" en revista Ecran, editada en $1946^{43}$.

De esta manera, a pesar de la difícil andadura de estas primeras mujeres en el circuito, ya en 1941 con el nombre de Dixie Lane, Mirella Latorre cantaba jazz en radio Sociedad Nacional de Agricultura, formando un trío integrado por Vicente Bianchi en piano y Ronnie Baker en batería ${ }^{44}$. Aunque Mirella, decía la crónica, "baila swing y le tiene un odio a la ópera", la mayor parte de las crooners eran mujeres con formación lírica, quienes ingresaban transitoriamente al campo de la música popular.

Otro caso fue el de Virginia Mills, "que se decía uruguaya, pero que Jack Brown jura que era antofagastina. Tenía voz de contralto y cantaba bonito" 45 . Pero sin duda la más destacada figura que abrió espacios fue Carmen Barros (Marianela), "la primera que se atrevió” según su coetánea y compañera lírica, Dina Murúa (Angélica Montes).

Resulta paradójico que, debido a la formación lírica, el camino de desarrollo de estas mujeres haya sido, simultáneamente, la causa de su exclusión. El proceso de canonización del jazz en relación con la música docta constituyó uno de los

41 Ecran, 1168 (9 de junio de 1953), p. 18.

42 Ubicado en Monjitas casi al llegar a la calle Merced, en Santiago de Chile.

43 Écran, 797 (30 de abril de 1946), p. 21.

44 Peña 2002: 174.

45 Muñoz Romero 1986: 15. 
referentes en el que se fue definiendo el género; aquello ha sido descrito como pregnancia ${ }^{46}$ de géneros musicales en formación, ya sea por asimilación, ya sea por diferencia, respecto del sistema musical o la industria cultural. Esto produjo un efecto respecto del modo en que las mujeres fueron evaluadas por los jazzistas masculinos, según se definieran por oposición a lo docto (el jazz no es docto) o por oposición a lo comercial (el jazz no es comercial). Así, durante la primera mitad del siglo XX las mujeres de formación vocal lírica fueron discriminadas o relegadas por aquellos jazzistas autodefinidos por oposición a lo docto, para quienes la impostación vocal pareció demasiado artificiosa y estilizada para el jazz, y no bien avenida con lo "sucio" del sonido improvisado. Por otra parte, las mujeres dedicadas a la actividad popular melódica, cómica o revisteril (por la consideración de estas prácticas como "no artísticas"), fueron quedando al margen del jazz como arte, definido por oposición a lo comercial. Ante ello, buena parte de estas mujeres regresaron a lo lírico, mudaron de género, o derivaron hacia la locución radial. Este último representó un espacio que fue adquiriendo gran importancia en el desarrollo de las cantantes.

El modelo de lady crooner, ligado también al cine musical, mantuvo su regencia a lo largo de las décadas de 1940 y 1950. Paralelamente persistía la tradición de la cupletista, con su amaneramiento lírico, lo revisteril asociado a la danza y el atiplamiento cómico. Muchas lady crooners provenían del ámbito teatral y del cine, quizás porque la interpretación vocal concentrada en el timbre y rasgos suprasegmentales de la voz en conjunción con la expresión facial o gestual, necesitaba de cierta versatilidad cinética e interpretativa que el arte dramático también requería.

Las experiencias de teatro y jazz se dieron en la década de 1960, con Carmen Barros junto con Village Trío en la obra Contrapunto en diálogo y jazz, de 1966. O bien con el grupo de teatro ICTUS montando Libertad... libertad, con el acompañamiento del cuarteto de jazz de Oscar Acevedo en 1967. También en los años 60 hubo actrices conectadas con el jazz en los años 60, como Peggy Cordero (que también fue vedette) cantando en el Nahuel Jazz Club. Pero esto viene de mucho antes, de las cantatrices como Malú Gatica, la misma Carmen Barros o Kerry Keller, quienes interpretaron con cierta regularidad repertorio norteamericano, junto con su actividad teatral. Respecto de esta última, tuvo una corta pero intensa carrera en el jazz antes de concentrarse definitivamente en el teatro. Fue considerada por la prensa como una reina local del jazz. Un recorte de diario, que ella misma nos facilitó (gracias a su esposo que coleccionó los artículos de diario donde Kerry aparecía), exhibía el siguiente titular: "Kerry Keller, reina del jazz chileno" 47 .

46 El jazz y el tango se han descrito como "géneros-figura" frente a otras músicas que operan como "géneros-fondo". Sobre este punto ver Jáuregui 2010: 83-93.

47 Para la relación existente entre los medios de comunicación (como fuentes de memoria e historia, así como de sustento y construcción de olvidos) y el discurso historiográfico ver: Haiquel 2005. 
Amalia Keller Rossenblat nació en Buenos Aires en 1919, pero a los tres años de edad se trasladó a Chile y realizó toda su vida artística en nuestro país. Radicada en Rancagua, a los 15 años, en 1934, se presentó y resultó contratada para cantar en radio El Mercurio y actuar en un programa llamado "La Hora en Broma”. En un periódico del mismo consorcio, consultada por los motivos que tuvo para iniciarse en el jazz, ella respondió: "Por una razón muy sencilla. A los 15 años yo ya hablaba correctamente el inglés, y al escuchar una audición en la cual se interpretaba jazz, sentí que yo podría ser crooner y me presenté a la radio, me escucharon y me dejaron cantar por el micrófono...".

Sus estudios de bachillerato en el Liceo de Aplicación prosiguieron paralelamente al canto, para ingresar posteriormente a la Universidad de Chile a estudiar Ciencias Económicas. Dejó estos estudios cuando Henry Kardos "se la lleva al Casino de Viña del Mar a cantar jazz para el público que bebe whiskey and soda, que fuma costosos puros habanos y que baila con desopilante gesto", señala una crónica periodística de la época. En 1939 Pablo Garrido la recuerda en las jam sessions realizadas por el Hot Club de Chile, donde también cantó la lady crooner Lucy Page Guevara, quien más tarde será la presidenta del Club de Jazz de Talca en 1980. En 1941 Kerry Keller viajó por primera vez a Buenos Aires, actuando durante unos meses en radio Splendid con la Orquesta de Kardos, presentándose también en el Alvear Palace Hotel con la Orquesta de Julio Rosenberg, y luego viajando a Rio de Janeiro, donde obtuvo mucho éxito.

De regreso a Chile, Kerry Keller actuó como lady crooner entre 1944 y 1946. Primero en la radio Sociedad Nacional de Minería, donde interpretaba spirituals acompañada por "un conjunto pequeño de jazz formado y dirigido por Theo Van Rees" ${ }^{48}$, formado por músicos chilenos, entre estos se encontraba el destacado trompetista Samuel de Rozas. En 1946 Ecran publicó:

"Los días martes y viernes, a las 21:30 horas, se ha estado transmitiendo desde el auditorium de Radio Sociedad Nacional de Minería, un espacio de media hora. Para su realización se ha llevado a los estudios a la lady crooner Kerry Keller, quien hace su temporada de despedida, acompañada por la orquesta de "jazz" de Lorenzo D'Acosta, músico chileno, ejecutante de saxófono y clarinete, y director del conjunto" 49 .

\footnotetext{
La historiografía representaría -a diferencia de la inmediatez del discurso periodístico- la búsqueda de un equilibrio trascendente entre la narración de la historia y una memoria "feliz" (Ricoeur) o "justa" (Todorov), que recupera el sentido y a sus protagonistas pese a las limitaciones.

48 Ecran, 696 (23 de mayo de 1944, p. 13. Van Rees, pianista, fue parte del conjunto Los Dixies.

49 Ecran, 800 (21 de mayo de 1946), p. 30.
} 


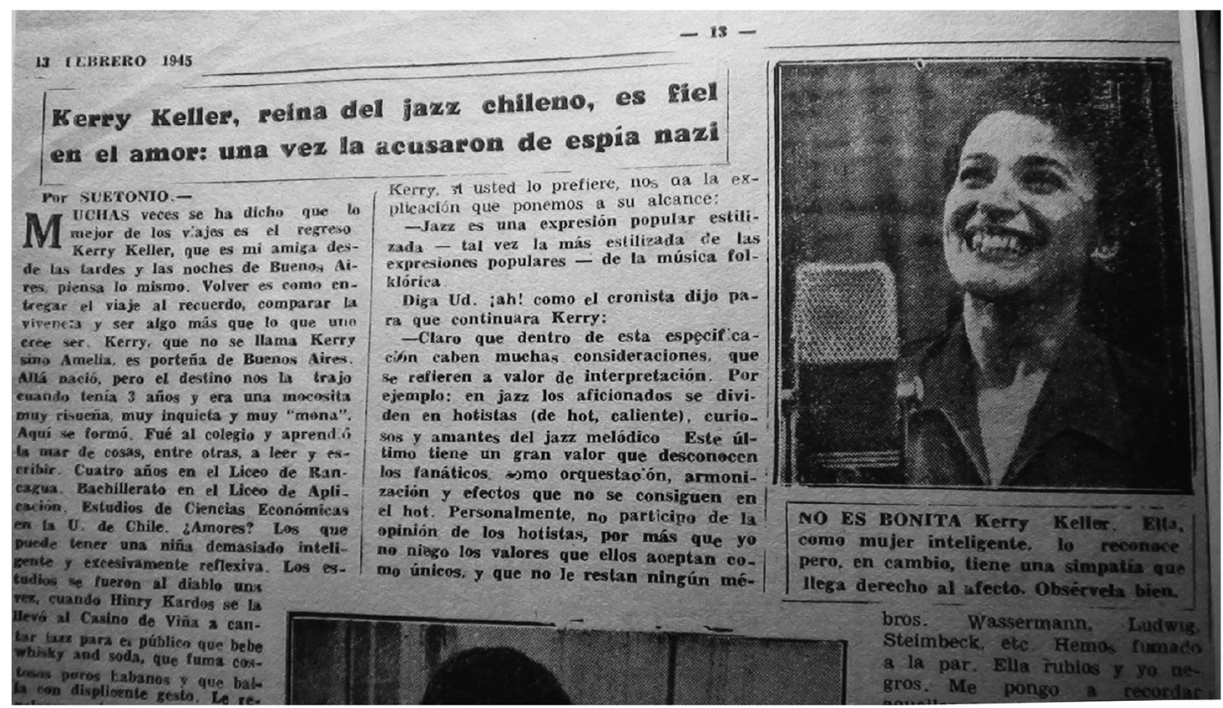

Foto 1. Kerry Keller, "Reina del jazz chileno”. Artículo periodístico del 13 de febrero de 1945 (fuente sin precisar).

$\mathrm{Al}$ año siguiente la encontramos actuando en la BBC de Londres. Antes de regresar a Chile pasó por España. A fines de 1967 Kerry interpretó a una cantante negra en el tercer cuadro de Fulgor y muerte de Joaquín Murieta de Pablo Neruda. En dicho cuadro (un cabaret de California), oscurecida su piel con maquillaje, entonó un desgarrador spiritual. Durante sus últimos años, Kerry Keller vivió en las afueras de Santiago, en Pirque, junto con una de sus hijas y rodeada del cariño de sus nietas y amigas actrices, sobre todo de Bélgica Castro, con quien mantuvo una amistad de años.

\subsection{La lady crooner como transición entre la vedette y la cantante de jazz.}

La figura de la lady crooner representó la transición entre la vedettey la cantante. No poseía todavía la libertad y autonomía de esta última, pero había dejado atrás la sujeción a lo dancístico y escénico de la vedette. Tras la penetración de la balada, en contigüidad con el swing, la cantante brillará por su voz, amplificada por el micrófono y un repertorio de melodías difundidas por la radio. El cancionero es primeramente norteamericano y en inglés. La estrella de la canción enarbolaba los valores de la elegancia, sensualidad y sofisticación, dejando entrever, pero cubriendo su cuerpo hasta reducir las partes expuestas solo al rostro, amplificado en el close up del imaginario cinematográfico. Asimismo ocurría con los hombros y brazos (las manos con frecuencia se recubrirán con guantes), y en algunos casos, los más atrevidos, descubriendo parte de la espalda. Se trataba de un traje que cubre y descubre. Tapa y deja ver en la idea del erotismo clásico, en consonancia con cierta "serenidad" natural, propia de la estrella de Hollywood. 
El desarrollo de una personalidad musical en equilibrio con la capacidad histriónica interpretativa fue fundamental. La utilidad de la actuación en la interpretación de letras fue recíproca con la importancia que se asignaba a la música en el paso de la actuación teatral a la cinematográfica. En 1945 Hans Jahr publicó en Viña del Mar un curso para ser estrella de cine, donde afirmaba que lo admirable (a emular) de la "estrella de Hollywood" era el equilibrio entre el estado interior del cuerpo y la expresión natural, para ello resultaba vital "consolidar o reconstruir la personalidad por medio de música sugestiva" 50 .

Fue entonces cuando las mujeres de clase media o alta (aun contando con la reprobación de las familias más aristocráticas) subieron al escenario en el rol de lady crooner. En la senda del negro spiritual y la balada swing encontramos a Malú Gatica (María Luz Enriqueta Gatica Boisier), adolescente de dieciséis años que vivía desde los siete en Nueva York, donde su padre trabajaba para la cadena National Broadcasting. En 1951 cantó en radio Minería, secundada por Trébol Trío con Hernán Prado en piano, Arturo Ravelo en contrabajo y Pancho Blancheteau en guitarra ${ }^{51}$.

Paralelamente hallamos en actividad a Carmen Barros de Amunátegui, hija del diplomático Tobías Barros Ortiz, quien fue edecán militar del presidente Arturo Alessandri, embajador en Roma y canciller del primer gobierno de Carlos Ibáñez, y a Inés Délano, cuya genealogía se entronca con el presidente de Estados Unidos, Franklin Delano Roosevelt. Eran mujeres consideradas de clase social alta, que ingresan al campo musical en la medida que el jazz se convertía poco a poco en marca de distinción enclasante, en el sentido que plantea Pierre Bourdieu ${ }^{52}$.

Ha señalado Vicente Bianchi ${ }^{53}$ que las hermanas Budge de Ferrari, bautizadas como The Humming Birds, no gustaban de aparecer con sus nombres reales, los que eran evitados o, en el caso de numerosas cantantes, directamente cambiados por un bautismo de norteamericanización. Así ocurrió con la cantante Dolores Díaz, crooner que en la década de 1940 comenzó a llamarse Doris Day (igual que la actriz norteamericana), o incluso el mismo Bianchi, rebautizado como Bob Sanders. "Las buenas familias no gustaban que sus hijas o señoritas aparecieran cantando en cabarets o restaurantes", recuerda Bianchi, testigo de la época y formador de varios tríos de mujeres.

En paralelo a la irrupción de la ideología del star system hollywoodense, en que las mujeres de "buenas familias" comenzaban a ingresar al campo, persistía y seguía desarrollándose la corriente revisteril con la mujer asociada a los bailes como bataclana o tiple en "fantasías de jazz", o bien como "gorda cómica", única forma que el aspecto físico de una mujer no sensual pudo tener un rol en ese tipo de espectáculo. El caso más destacado de Chile fue el de la actriz Olga Donoso, quien cantó algunas rutinas con one-step exhibiendo su físico corpulento. Otra situación asociada a lo cómico y el jazz lo encontramos en la parodia del scat que la actriz Ana González hizo en 1943 del tema "Yo quiero ser estrella", ya mencionado.

50 Jahr 1945: 31.

51 Ecran, 1082 (16 de octubre de 1951): 18.

52 2012: 572 .

53 En entrevista concedida al autor en julio de 2009 para el programa "Holojazz" de radio Universidad de Chile. 
La lady crooner fue necesaria e importante para las orquestas, pero -como ocurría usualmente con todos los crooners, hombres o mujeres- subsidiaria y solo destinada a cantar las letras, después de ello muchas veces permanecía sentada al costado. Además de la orquesta de Vicente Bianchi, que abordaba los repertorios populares y clásicos, hubo otras orquestas que recurrieron durante la década del 40 y 50 a mujeres cantantes para el repertorio popular. En la Orquesta Jazz de Federico Ojeda la crooner o croonette era Marie Louise, una norteamericana radicada en Chile y esposa del saxofonista de la agrupación. Mary Louise, como a veces también escribían su nombre, cantaba en 1949 acompañada por Ojeda en radio Minería. En la orquesta de Izidor Handler la crooner era Elly Morgan, quien cultivó en Chile el modelo de Billie Holiday. En 1949 la revista Antena de radio Minería comentaba que "dejó sus estudios de pedagogía en inglés en la Universidad de Concepción para dedicarse al radioteatro y a las canciones" 54 . Ese mismo año se presentaba en el teatro Oriente con transmisiones por radio Minería. El baterista Lucho Córdova recuerda haberlo visto cantar y haber reconocido de inmediato su bellísima voz:

"Elly Morgan fue una extraordinaria y popular cantante, esposa de mi amigo el pianista y astrónomo aficionado Federico Waelder, con quien compartimos muchas veces los cielos y el jazz en Antofagasta. Cantaba como Billie Holiday, se ponía una flor en el pelo. Era una mujer muy bella, con una tez morena que le daba un aspecto muy parecido a Lady Day. Una excelente cantante" ${ }^{55}$.

La denominación "orquesta jazz" no era restrictiva del género ya que podía perfectamente interpretar otros estilos, como tango y rumba. Probablemente su multiplicidad y heterogeneidad provengan de la concepción de la jazz band de los años 20. El one-step "Los del jazz", mencionado anteriormente, dice: "Somos de la jazz band / alegres componentes que a diario en el danzant / actuamos complacientes / damos vida al foxtrot y al tango sensación / no hay quien nos compita en tocar danzones ni en tocar machichas, one-step, vals o charleston" 56 .

No es raro que ese formato orquestal haya influido en las formas de las orquestas radiales, que eran funcionales al repertorio de todos los géneros y que estaban definidas por la cantidad y tipo de instrumentos más que por los géneros propiamente tales, pues la especialización de los géneros estaba aún en curso. Todavía en la segunda mitad del siglo XX era normal la contigüidad melódica del tango y el vals con los bailes de jazz ${ }^{57}$. La existencia de la Carlos Gardel Jazz Band, una curiosa banda familiar que celebraba en 1954 sus 19 años de existencia ${ }^{58}$, o la noticia de Nano Moya y el vals "Amémonos, en jazz" anunciada como grabación con orquesta jazz en $1950^{59}$ son ilustrativas al respecto. La función del crooner no

54 Antena de la Radio Minería, I/6 (1 de septiembre de 1949), p. 4.

55 Entrevista concedida al autor en septiembre de 2012.

56 Arreglo y letra de Roberto Retes B. Editado por Casa Amarilla. S/F.

57 Para ver la relación entre jazz bandy tango revisar Jáuregui 2010: 83-93.

58 Ecran, 1229 (10 de agosto de 1954), p. 15.

59 Ecran, 998 (7 de marzo de 1950), p. 21. 
era genéricamente exclusiva, pues debía ejecutar diversos géneros, así como antes lo habían hecho las tiples.

El listado de las mujeres que en Chile ejercieron de lady crooner es largo. Una de las menos conocidas fue Gladys Ocampo. En 1949 la encontramos actuando con la Orquesta de Osvaldo Silva. Actuó en la boite Tap Room en la temporada de diciembre de ese año. Durante 1955 Ocampo se presentó en radio Corporación como integrante crooner del quinteto Los Manhattans. Cantaba en inglés e italiano. En un comentario aparecido en la revista Ecran del 2 de agosto de 1955, se evaluaba como deficiente el trabajo de la crooner, pues "no vocaliza bien, produciendo la impresión de que no entiende o no se preocupa del contenido de la letra”. En la misma crónica se destacaba el desempeño del conjunto acompañante, integrado por el pianista Hugo Ramírez, con Alfredo Díaz en guitarra, Antonio Riquelme en batería y Fernando Quintana en contrabajo. En 1961 la encontramos ya convertida en excantante y locutora de radio Portales.

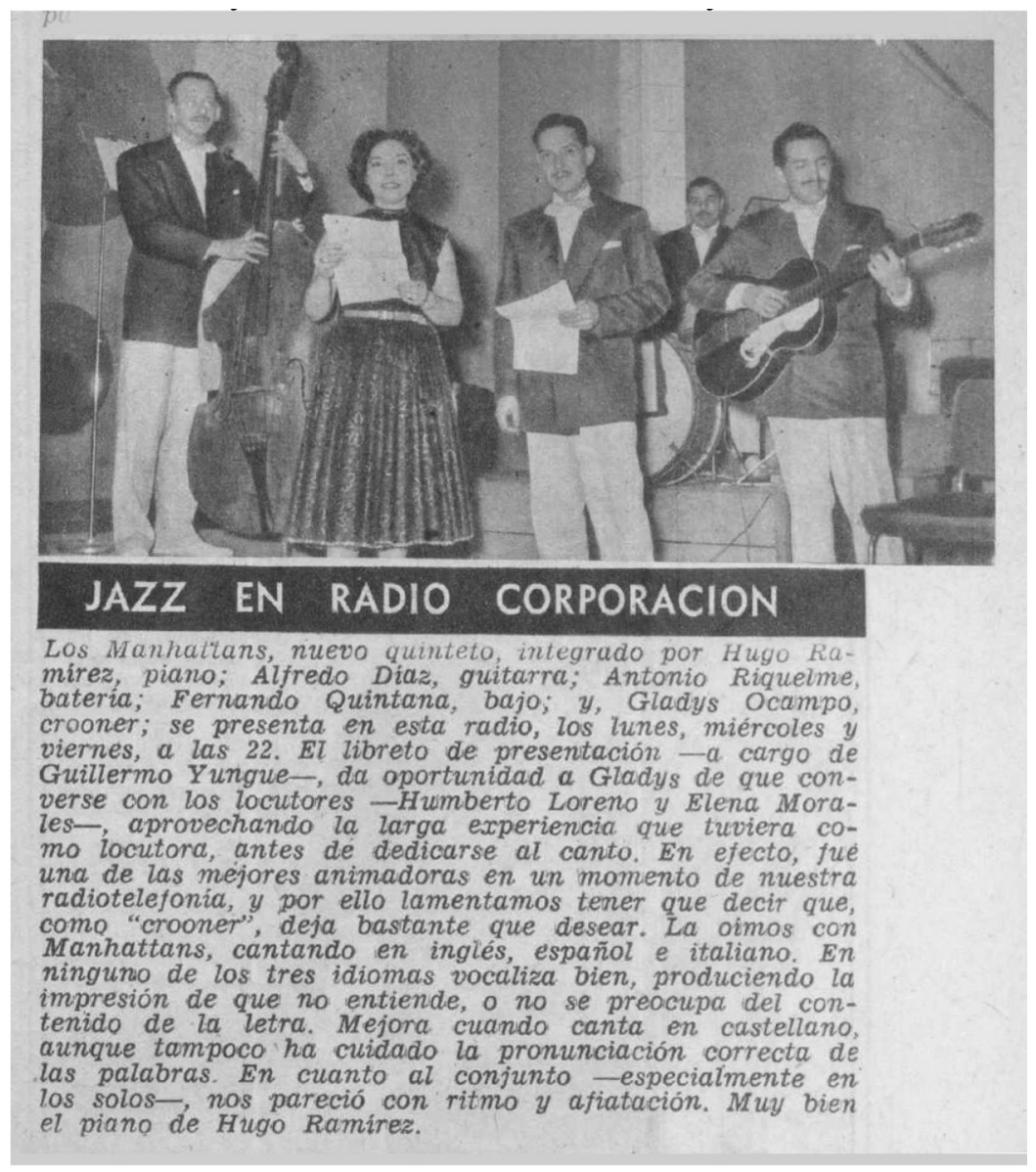

Foto 2. Gladys Ocampo con Los Manhattans en radio Corporación (Ecran, 2 de agosto de 1955, p. 19). 
Buscando datos acerca de esta destacada (pero olvidada) figura del canto de jazz y la locución en Chile, hallamos su nombre en los documentos desclasificados de la CIA (publicados por LOM en 1999), donde puede leerse: "a Gladys Ocampo, locutora radial, no se le permite salir del país a visitar a su padre que está exiliado y gravemente enfermo en México. Luego de un período de arresto domiciliario, fue expulsada del país. Su padre murió antes de que pudiera salir de Chile"60.

El baterista de jazz José Luis "Lucho" Córdova recuerda cuando su padre y el padre de Gladys fueron deportados por el régimen de Ibáñez del Campo a la isla de Chiloé en 193161. Gladys y Lucho Córdova compartieron infancia y juegos en ese insilio 62: "Entonces ella jugaba a las muñecas conmigo que era menor que ella. Yo era su juguete", recuerda el baterista, fallecido en 2015.

El paso del canto melódico y de jazz hacia la locución radial fue frecuente, mediado por el empleo de la amplificación electrónica, vital para el cambio de modelización en el desarrollo de la mujer en la música popular y el jazz. El micrófono (sobre todo radial) permitía disminuir las exigencias escénicoacústicas de atiplamiento y bajar el tono a un canto "más natural" o normal, de modo que desde las voces altas o soprano, propias del modelo español y francés, se transitó a las voces medias y graves (mezzosoprano y contralto) del modelo norteamericano. Junto con generar una cercanía o inmediatez, la voz adquiere rasgos interpretativos susurrantes de connotación afectiva, erótica o íntima. En los radioteatros la voz quedará eximida de los requerimientos acústicos operáticos del gran anfiteatro.

En la música, el paso del estilo lírico (presente en los modelos español y francés) al estilo natural o "moderno" será gradual. Incluso podemos encontrar en la década de 1960 cantantes atipladas que intentaban ajustarse a las nuevas exigencias del mercado musical. Así, Lucía Silva (hija del cantante lírico Gabriel Silva) se presentaba en Chile como Lucía D’Anselmo y en EE.UU. como Lucía Da Silva, cantando en Nueva York, donde compartió escenario con Sammy Davis Jr. Ella afirmaba en 1967 que "En EE.UU. me transformaron el estilo. Abandoné el tono lírico: tengo ahora uno más moderno"63. Los modelos a emular también cambiaban: Perla Fox, que grabó repertorio norteamericano, siguió el registro mezzosoprano de Jane Froman, mientras que Elly Morgan cultivó el modelo contralto de Billie Holiday. En este descenso hacia el tono grave (contralto), incluso hubo mujeres que en los años 60 imitaron por momentos el tono gutural de Louis Armstrong, como Luz Eliana.

La mayor cantidad de referencias acerca de lady crooners o croonettes surgen a partir de las décadas de 1940 y 1950. En los años 60 aparecieron recién las

60 Villegas 1999: 165.

61 Córdova tenía entonces 4 años. La fecha de nacimiento del baterista, 1921, fue probablemente 1927, pues hay dudas respecto de su real fecha de nacimiento.

62 Se ha llamado "insilio" a la situación de quienes permanecen en el país durante una dictadura, en una experiencia más definida por negaciones, relegación y represión interna que por exilios como expatriaciones. Oroño (2017: 38).

63 Ecran, 1887 (4 de abril de 1967), p. 21. 
primeras cantantes de jazz propiamente, con Sophie Brown. Se trataba de la variante sublimada de la actividad jazzística. Sin embargo, en paralelo, el mundo del jazz siguió proyectándose y practicándose en cabarets, boites, teatros de revistas, quintas de recreos o sencillamente en prostíbulos, donde la performance de jazz efectivamente existió; sin programa ni regularidad, de manera espontánea y no publicitada, obviamente. Lugares como La Nena del Banjo (porque, se decía, la regenta tocaba el banjo) o donde La Pancha (que habría sido compañera del trompetista Lucho Aránguiz), locales ubicados en los callejones de calle 10 de Julio, eran lugares donde no pocos jazzistas en la década del 40 y 50 llegaron a solazarse y ocasionalmente tocar jazz con los instrumentos de "la casa". Aquello constituyó un entorno fascinante que funcionó incluso como remanso para la ajetreada vida nocturna de algunos músicos jazzistas. Algunas de las mujeres que trabajaban allí mantenían relaciones personales, ya sea de amistad o pareja, con músicos aficionados o profesionales del circuito ${ }^{64}$.

Para las cultoras del género, el acceso al repertorio muchas veces se daba por "affidamento", entendido como el traspaso cotidiano de experiencias y modelos de vida entre mujeres mediante consejos, apoyos y relatos íntimos. No es extraño que la "nana" y "la señorita de la casa" dialogasen horizontalmente, mediadas por su vínculo de género. Malú Gatica aprendió a cantar blues y negro spirituals de su nana negra en Harlem. Era habitual que las propias mujeres solidariamente compartieran su acercamiento doméstico al jazz, incluso en la intimidad con que se abordaba la enseñanza particular por ellas. Un caso de esto último hallamos en los cuadernos que Inés Délano asignaba para cada alumno/a. No obstante, esta unidad no superará la posterior fragmentación de los vínculos, formando una especie de "des-grupo" de amigas, examigas y des-amigas que a la distancia están sabiendo unas de otras, pero sin reunirse nunca.

Teresa Orrego Salas (1921-2017) ${ }^{65}$ interpretó negro spirituals con el quinteto vocal The Georgians entre 1943 y 1945. Formó parte de un grupo de alumnas de Clara Oyuela, integrado también por Dina Murúa y Carmen Barros, quien fuera a juicio de Dina la primera en despegarse del canon docto (común a todas ellas) y en liderar la transición hacia las cantantes de jazz, sin que ninguna lo fuera exclusivamente. La misma foto en que aparecen interpretando Sor Angélica de Puccini permanece sobre el piano de Dina Murúa y también, a pocas cuadras en el mismo sector de Santiago, en la casa de Teresa Orrego Salas.

64 De acuerdo con el testimonio recogido en entrevista al baterista José Luis Córdova Ballesteros, en 2012.

65 Hermana del compositor Juan Orrego Salas, e hija de Filomena Salas, quien publicó en la revista Marsyas, 9 (noviembre-diciembre 1927), pp. 317-321, una traducción-adaptación del texto en francés "Le Jazz", escrito por el musicólogo belga Arthur Hoerée y publicado en Europa ese mismo año. Está pendiente un estudio más profundo de esta traducción-adaptación de Salas, pero está claro que en términos de género social (gender) no cuestiona sino más bien reafirma una hegemonía masculina omnímoda en el emergente mundo chileno del jazz, cuyos representantes (epígonos de Pablo Garrido) se afanaron en reconocer discos, instituciones y actos públicos de consagración eminentemente masculinos, obviando lo doméstico y ágrafo del actuar femenino. 


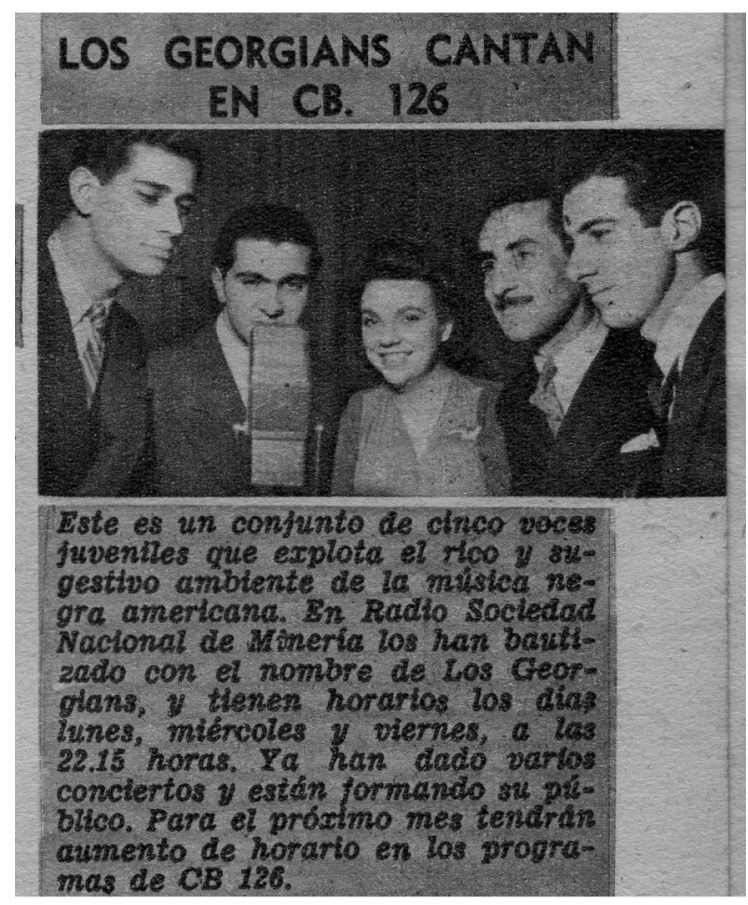

Foto 3. Los Georgians cantan en CB. 126, radio Sociedad Nacional de Minería.

"Un conjunto de cinco voces juveniles que explora el rico y sugestivo ambiente de la música negra americana" (Ecran, 24 de agosto de 1943, p. 15).

$\mathrm{Al}$ entrevistar a las últimas sobrevivientes chilenas de la actividad jazzística en la década de 1940, comprobamos la tensión en que les tocó vivir. Para ellas las opciones fueron asociarse a la música popular melódica o revisteril (y el jazz en ella) quedando bajo el estigma de mujer pública (connotación inaceptable para las hijas de "buena familia"), o bien validarse mediante el conducto académicoprofesional de la actividad lírica, ingresando a la práctica del jazz por medio de los negro spirituals (repertorio adscrito al jazz tradicional), el repertorio del songbook o cancionero norteamericano, la práctica instrumental (generalmente subsidiaria de la voz y muchísimo más escasa) o, en su defecto, sencillamente abandonar la música. No es casualidad que en 1934 la revista Margarita llamara a las mujeres a abandonar el piano de ayer (la música) en pro del "teclado que imprime" de hoy, aludiendo al secretariado profesional ${ }^{66}$. Es decir, la música como actividad doméstica, sí; de profesión, jamás! Y cuando las mujeres definitivamente accedían a la

66 Margarita, I/30 (23 de noviembre de 1934), p. 28. 
práctica del jazz, el ejercicio del arte las circunscribió a las esporádicas ventanas canónicas que su rol de madres o esposas les permitía. Mientras fueran solteras, la industria cultural las reorienta de acuerdo con las necesidades del mercado (un eufemismo, a causa de su control masculino), retrasando, interrumpiendo, postergando o sesgando sus prometedoras carreras al derivarlas hacia repertorios melódicos más populares, como ocurrió a Rita Góngora o Luz Eliana durante la Nueva Ola.

Entonces no fue raro que hayan sido muchas más las ejecutantes esporádicas y aficionadas que las de dedicación exclusiva y con carrera. Los casos de Lucy Page (quien en 1980 celebró sus 80 años con la Retaguardia Jazz Band), la pianista Inés Pizarro, las cantantes Magdalena ${ }^{67}$ (soprano que en 1951 cantó repertorio norteamericano con The Strangers, dirigidos por Theo Van Rees), Inés Carmona, Perla Fox, Laura Hernández, Mirella Latorre, Sonia La Única (que formó parte del quinteto vocal de negro spirituals Los Georgians en $1951^{68}$ y también integró The Strangers), son parte de una historia hecha más de discontinuidades y grietas que de madeja continua. A ellas habría que agregar, en el periodo post-crooner, las historias de vida de Nelly Sanders, Rita Góngora y Luz Eliana.

\section{CONCLUSIONES}

A partir de este cuadro, en conjunción con los dos regímenes simbólicos y los dispositivos discursivos que hemos trazado, observamos cómo el memorando androcéntrico de una "memoria emblemática" 69 seleccionó y organizó las memorias colectivas del jazz dentro y fuera del circuito. No hubo una visión alternativa, contraparte o disidente frente a esta mirada androcéntrica. Esto proyectó inicialmente la historia del jazz a semejanza de la evolución lineal de la música clásica, a partir de un cierto número de biografías masculinas encarnadas en un grupo de all stars o héroes del jazz en Chile, con supremacía de lo instrumental asociado al mito del genio y el virtuosismo del control sobre el instrumento, por sobre lo vocal, que lo hubo, pero subsidiario de lo instrumental. Esos criterios fueron orientadores del proceso de institucionalización y canonización del jazz en nuestro medio, así como ocurrió en otras partes del mundo. Con el paso del swing al bebop, este proceso consumó la creciente academización del género ${ }^{70}$, lo que en la práctica ha conllevado a conceptualizar al jazz como música de arte, y por tanto, como música "clasicizada"71, quedando de manera ecléctica a veces excluida y otras incluida en la música popular. Asimismo también se ha dado

67 Ignoramos hasta hoy el apellido de esta cantante, parece tratarse de un seudónimo.

68 Ecran, 1085 (6 de noviembre de 1951), p. 18.

69 Stern 2000: 3.

70 Ochoa 2011: 83.

71 Hamilton 2010: 64. 
una cierta "jazzificación de la música clásica"72. No obstante, mientras el jazz mantuvo un pie en cada ribera, el vector de género se mantuvo, vía genealogía patriarcal, unilateralmente androcéntrico. Esto significó construir un archivo de memoria que no ha sido feliz ni equitativo para todos, ya que excluyó a un sector de su comunidad oficiante por razones de género y canon ${ }^{73}$.

Excluidas y encasilladas por una cultura patriarcal como reinas o bataclanas, divas o cómicas del jazz, las ausentadas han estado ampliando los espacios que esas circunstancias les permitieron. Ya sea cantando, bailando o componiendo, ellas han sostenido dentro de la historia patrilineal un espacio más allá de lo accidental, discontinuo o parentético que la historiografía y crítica les ha permitido. Así aspiran a una "habitación propia"74 que sigue invisibilizada por el escaso "impacto" institucional o musical canónico que se les ha reconocido. Además, han sido convertidas en "sujetos sin historia", debido a la escasez de documentación 75 o registro musical.

El largo olvido que ha velado la presencia de las mujeres en el jazz de Chile ha sido mucho más que un inocuo lapsus, involuntario o irresponsable. Ha estado operando en la práctica como una amnesia colectiva, acrítica y normalizada desde la óptica androcéntrica de un jazz profesionalizado por un mundo masculino y un discurso historiográfico y crítico que lo consagra. En este sentido, la participación de la mujer ha sido vista y considerada como un hecho excepcional y colateral. Su empoderamiento en el campo musical y artístico ha tomado la forma de un sujeto interdicto frente al modo masculino como norma, pasando de objeto a sujeto, en lo que María Angélica Illanes ha denominado "la batalla de la memoria". Ello consiste en "reconstruir, a través de la reescritura crítica de la memoria, nuestra pertenencia a algún proyecto histórico capaz de reunir las piezas de nuestra fracturada tribu" 76 .

Mujeres de cuyos nombres no hemos querido acordarnos vivieron y cantaron acompañadas por grandes orquestas, aclamadas por un público que luego sencillamente las olvidó. No hubo tampoco demasiado interés por parte de los recordadores profesionales (historiadores, periodistas, críticos) por mantener viva su memoria para las generaciones venideras. Ahí están, sin embargo, vivas al otro lado del cristal. "Mala memoria la que solo funciona hacia atrás", dice la reina en Alicia a través del espejo. Escuchemos, entonces, en estas mujeres los vestigios de un futuro diferente y el canto de su amor por el jazz. Ojalá lo hagamos agradecidos, porque siendo más honestos y amorosos con ellas, lo seremos también con nosotros mismos.

72 Adorno 2008: 115.

73 McGee 2009: 172.

74 Campos Fonseca 2010: 4.

75 Garcés 2002: 12.

76 Illanes 2002: 16. 


\section{BIBLIOGRAFÍA}

Adorno, THEODOR

2008 "Sobre el jazz", Escritos musicales IV. Madrid: Akal, pp. 83-118.

Araujo, Kathya

2008 ¿Se acata pero no se cumple?: estudios sobre las normas en América Latina. Santiago de Chile: LOM Editores.

Armatte, Michel

2006 "La noción de modelo en las ciencias sociales", Empiria: Revista de metodología de ciencias sociales, 11 , pp. 33-70.

BAndura, Albert

1977 Social Learning Theory. Nueva York: General Learning Press.

Bourdieu, Pierre

2012 La distinción. Criterio y bases sociales del gusto. Buenos Aires: Alfaguara.

Brandi Vera, Pascual

1935 El Jazz. Santiago de Chile: Nascimento.

BRÜNNER, José JOAQUín

2002 Globalización cultural y posmodernidad. Santiago: Fondo de Cultura Económica.

Campos Fonseca, Susan

2010 “¿Una habitación propia en el 'Jazz latino’?”, Journal of the International Association for the Study of Popular Music, 1/2, pp. 1-11.

Citrón, Marcia

1993 Gender and the Musical Canon. Nueva York: Cambridge University Press.

Guneo, ANA María

1998 Para leer a Gabriela Mistral. Santiago: Cuarto Propio.

Delannoy, LuC

2005 Carambola. Vidas en el jazz latino. México: Fondo de Cultura Económica.

Deza, Francisco

1964 Panorama del jazz. Comité de jazz. Santiago: Instituto Chileno-Norteamericano de Cultura.

Ellis Benson, Bruge

2005 “Jazz: l'Autre exotique”, Horizons philosophiques, 1/16, 1 (otoño), pp. 86-100.

Errázuriz Larraín, Luis Hernán

1994 Historia de un área marginal. La enseñanza artística en Chile, 1797-1993. Santiago: Ediciones Universidad Católica de Chile.

Garcés, Mario

2002 Recreando el pasado: Guía metodológica para la memoria y la historia local. Santiago: ECO, Educación y Comunicaciones.

González, Juan Pablo y Claudio Rolle

2003 Historia social de la música popular en Chile. 1890-1950. Santiago: Ediciones Universidad Católica de Chile. 
Green, LucY

2001 How popular musicians learn: a way ahead for music education. Reino Unido: Ashgate Publishing Limited.

Guadarrama, Rocío y José Luis Torres

2005 "Identidades laborales en transición. Costureras y maestras de primaria en Costa Rica y México", Revista Centroamericana de Ciencias Sociales, 2/2, pp. 103-138.

Haiquel, Miguel Ángel, María de los Ángeles Montes y Alberto Valán

2005 "Memoria y olvido en la prensa gráfica. El crac de 1929 en los diarios La Voz del Interior y La Nación". Ponencia presentada en IX Jornadas Nacionales de Investigadores en comunicación, Córdoba, Universidad Nacional de Villa María. Red Nacional de Investigadores en Comunicación. Disponible en http:/ / sm000153.ferozo.com/memorias/p_jornadas_p.php?id=910\&idj=9.

Hamilton, ANDY

2010. "Jazz as classical music”, Improvisation: Between Technique and Spontaneity. Editado por Marina Santi. Reino Unido: Cambridge Scholar Publishing, pp. 53-76.

IHNEN, BERNARDITA

2012. Trabajo y Jazz. Un acercamiento estadístico y cualitativo a las formas de trabajo y de representarse desde el trabajo en los músicos de jazz del circuito santiaguino. Profesora guía: Marisol Facuse. Tesis para postular al título de Socióloga. Santiago: Universidad de Chile, Facultad de Ciencias Sociales. Inédita.

Illanes, María AngÉlica

2002 La batalla de la memoria. Santiago: Planeta.

JaHR, Hans

1945 ¿Cómo llegar a ser artista de cine? Viña del Mar: Autoedición.

Jáuregui, Isabel ANABel

2010 "Orquesta típica y Jazz band. Contrapuntos mediáticos", Revista Lis III/5 (marzojunio), pp.83-93.

Kaufmann, Helen L.

1937 From Jehovah to jazz. Music in America from psalmody to the present day. Nueva York: Dood, Mead \& Company.

López CANo, RubéN

2007 Música e intertextualidad, Disponible en: http://lopezcano.org/Articulos/2007. intertextualidad.pdf.

Marino, Juan y Eva Martinic

s/f Guía de la música popular en Chile, desde 1800 a 1980. (inédito)

MGgee, Kristin A.

2009 Some Liked It Hot: Jazz Women in Film and Television, 1928-1959. Middletown, Connecticut: Wesleyan University Press.

Menanteau, Álvaro

2006 Historia del jazz en Chile. Santiago: Ocho Libros.

Mignolo, Walter

1981 "El Metatexto Historiográfico y la Historiografía Indiana", MLN 96/2, Hispanic Issue (marzo), pp. 358-402. 
Mistral, Gabriela

1979 Grandeza de los oficios. Santiago: Andrés Bello.

Montecino Aguirre, Sonia (Compiladora)

2008 Mujeres chilenas. Fragmentos de una historia. Santiago de Chile: Catalonia,

Muñoz Romero, Osvaldo (Rakatán)

1986 ¡Buenas noches, Santiago! 50 años del espectáculo nocturno. Santiago: s/e.

Ochoa Escobar, Juan Sebastí́n

2010 "Los discursos de superioridad del jazz frente a otras músicas populares contemporáneas", El artista, 7 (diciembre), pp. 11-27.

2011. "El canon del jazz en Colombia: una aproximación a través de artículos periodísticos”, Cuadernos de Música, Artes Visuales y Artes Escénicas, 6/1, pp. 81-102.

Oroño, Tatiana

2017 Libro de horas, Montevideo: Estuario.

Quintana Martínez, Alejandra

2009 Perspectiva de género en el Plan nacional de música para la convivencia. Bogotá: Ministerio de Cultura de Colombia.

PANOFSKY, ERWIN

1995 Three Essays on style. Cambridge: MIT Press.

Peña Fuenzalida, Carmen

2008 "El cuerpo en la escena. Papel de las mujeres chilenas en el desarrollo de la música y el canto", Mujeres chilenas. Fragmentos de una historia. Editado por Sonia Montecino Aguirre. Santiago: Catalonia, pp. 297-310.

Peña Muñoz, Manuel

2002 Los cafés literarios en Chile. Santiago: RIL.

SARGEANT, WinTHROP

1975 Jazz, hot $\mathcal{E}$ hibryd. Nueva York: Da Capo Press.

SCHULler, GUNTHER

1998 "Jazz and music exoticism", The exotic in western music. Editado por Jonathan Bellman. Texas: Northeastern University Press, pp. 281-291.

Stern, Steve

2000 "De la memoria suelta a la memoria emblemática. Hacia el recordar y el olvidar como proceso histórico (Chile: 1973-1998) ”, Memoria para un nuevo siglo: Chile, miradas a la segunda mitad del siglo XX. Editado por Mario Garcés y otros. Santiago: LOM, pp. 11-76.

TARSE, JEAN

1959 Le jazz: De la bamboula au be-bop (Marabout-flash), Editions Gérard et C, Verviers.

TOMLINSON, GARY

1991 "Cultural dialogics and jazz: A white historian signifies". Black Music Research Journal, 11/2, pp. 229-264.

Villegas, Sergio

1999 Archivos secretos: documentos desclasificados de la CIA. Santiago: LOM. 
Vizer, EdUARdo A.

2009 "Modelización del conocimiento social: la comunicación como estrategia de apropiación expresiva de los mundos sociales”, Perspectivas de la comunicación, 2/2, Temuco: Universidad de La Frontera, pp. 85-97.

\section{ENTREVISTAS}

Carmen Barros. Entrevista en Holojazz (radio Universidad de Chile), octubre de 2010.

Vicente Bianchi. Entrevista realizada en su domicilio, en La Reina, en julio 2009.

Lucho Córdova. Entrevista realizada en su domicilio, en septiembre de 2012.

Giovanni Cultrera. Entrevista en Holojazz (radio Universidad de Chile), en abril de 2017.

Inés Délano. Entrevista realizada en su domicilio, en noviembre de 2008.

Kerry Keller. Entrevista realizada en su casa en Pirque, en febrero de 2013.

Simone Racz (hija de Teresa Orrego). Entrevista realizada en su depto., en mayo de 2012.

\section{REVISTAS CONSULTADAS}

Antena de la Radio Minería, año 1949.

Ecran, años 1943, 1944, 1946, 1950, 1951, 1953, 1954, 1955, 1967.

Margarita, año 1934.

Marsyas, año 1927. 